\title{
Effects of TSH on Erythrocyte Osmotic Fragility: Signaling Pathway
}

\section{Evelyn Mendonça-Reis ${ }^{1,3}$, Camila Cristina Guimarães Nobre ${ }^{1,3}$, Artur Paes-Chagas ${ }^{1,3}$, Leandro Miranda-Alves $^{2,3,4}$ and Clemilson Berto-Junior ${ }^{1,2,3,5^{*}}$}

${ }^{1}$ Grupo de Pesquisa em Fisiologia Eritróide - GPFisEri, Universidade Federal do Rio de Janeiro, Campus Macaé, Brazil

${ }^{2}$ Laboratório de Endocrinologia Experimental- LEEx, Instituto de Ciências Biomédicas, Universidade Federal do Rio de Janeiro, Brazil

${ }^{3}$ Programa de Pós-graduação em Endocrinologia, Faculdade de Medicina, Universidade Federal do Rio de Janeiro, Brazil

${ }^{4}$ Programa de Pós-graduação em Farmacologia e Química Medicinal, Instituto de Ciências Biomédicas, Universidade Federal do Rio de Janeiro, Brazil

${ }^{5}$ Faculdade de Farmácia, Universidade Federal do Rio de Janeiro, Campus Macaé, Brazil

*Corresponding author: Clemilson Berto Junior, Ph.D., Universidade Federal do Rio de Janeiro, Campus Macaé, Faculdade de Farmácia, Av. Aluizio da Silva Gomes, 50- Novo Cavaleiros, Macaé, 27930-560, Rio de Janeiro, RJ, Brazil, Tel: 55-21-98081-3681

\begin{abstract}
TSH is a peptide hormone synthetized and secreted by pituitary with fundamental importance for thyroid function. TSH receptors are found in other tissue than thyroid playing diverse roles, including erythrocyte. Based on the fact that deformability is one of the most important features of a mature erythrocyte, we aimed to verify if TSH modulates erythrocytes volume and, if does, which signaling is involved in this modulation. Using hemolysis assay, we create a hemolysis curve of erythrocyte in presence of TSH in different concentrations (1, 2, 3 and $5 \mathrm{mlU} / \mathrm{L})$. By adding AICAR, Wortmannin and Akt $1 / 2$ inhibitor, it was possible to observe whether these pathways had an influence on TSH-reduced hemolysis in specific $\mathrm{NaCl}$ concentration of $0.4 \%$. Changing concentrations of $\mathrm{NaCl}$ from 0.1 to $0.9 \%$ was accompanied by marked hemolysis in very low sodium chloride concentrations of $0.1,0.2,0.3$ and $0.4 \%$ and a substantial decrease in hemolysis in 0.5 to $0.9 \%$ of $\mathrm{NaCl}$ occurred in control treatment. After TSH treatment, all concentrations tested were able to reduce significantly hemolysis in $0.4 \% \mathrm{NaCl}$. AICAR, Wortmannin and Akt 1/2 inhibitor reversed the effect of TSH in all concentrations. In conclusion, we observed that TSH ranging from 1 to $5 \mathrm{mlU} / \mathrm{L}$ improves $\mathrm{RBC}$ resistance to hemolysis and this effect is made by inhibiting AMPK-dependent pathway and concomitant activation of PI3K/Akt signaling pathway.
\end{abstract}

\section{Keywords}

TSH, Erythrocyte, Osmotic fragility, Signaling pathway

\section{Introduction}

Thyroid-stimulating hormone (TSH) is a peptide hormone synthetized and secreted by pituitary with fundamental importance for thyroid function and balance, affecting iodine uptake, thyroxine and triiodothyronine production and, as a consequence, whole body metabolism [1,2]. It acts through thyroid-stimulating hormone receptor (TSHr), a classical seven transmembrane G-protein coupled receptor [3], being usually coupled to Gas, increasing cAMP production and activation of PKA or even to Gaq and either activating Ras/Raf/Mek/ Erk or PI3K/Akt signaling pathways [4].

TSH receptors are found in other tissue than thyroid playing diverse roles. In brown adipose tissue it was demonstrated that TSH increase lipolysis, inhibit leptin mRNA and increase $\mathrm{O}_{2}$ consumption with Erk and Akt phosphorylation [5] and also acts as a survival factor via PI3K/Akt in 3T3-L1 preadipocytes cell model [6]. mRNA and protein expression of TSHr was detected by Crisanti, et al., in primary cultured human astrocytes besides

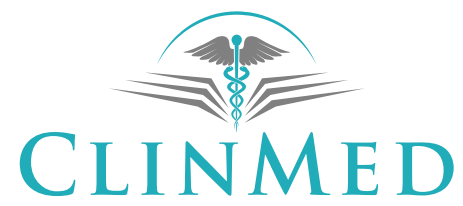

INTERNATIONAL LIBRARY

Citation: Mendonça-Reis E, Nobre CCG, Paes-Chagas A, Miranda-Alves L, Berto-Junior C (2020) Effects of TSH on Erythrocyte Osmotic Fragility: Signaling Pathway. Int J Blood Res Disord 7:048. doi. org/10.23937/2469-5696/1410048

Accepted: March 07, 2020: Published: March 09, 2020

Copyright: (C) 2020 Mendonça-Reis E, et al. This is an open-access article distributed under the terms of the Creative Commons Attribution License, which permits unrestricted use, distribution, and reproduction in any medium, provided the original author and source are credited. 
neuronal cells [7]; TSH also was able to increase hepatic gluconeogenesis via cAMP/PKA pathway [8]. In the same way, Nicolini and co-workers showed that erythrocyte of patients with subclinical hypothyroidism has increased number of ouabain-binding sites and latter ratified the presence of TSHr in these cells with co-immunoprecipitation $[9,10]$. These data points to the paradigm of functional TSHr in erythrocytes and remarks a possible role of hormone actions in nonthyroidal cells.

Erythrocytes are cells responsible mainly for gas exchange process, so it is necessary a high degree of deformability in order to facilitate their passage through reduced caliber vessels and thus oxygenate tissues [11]. This deformability is conferred by several factors such as a high area-volume ratio (conferred by the biconcave disc shape) and the degree of fluidity of the plasma membrane [12]. Thus, deformability is one of the most important features of a mature erythrocyte, with several factors affecting it. PI3K/Akt signaling pathway in erythrocytes along with nitric oxide synthetase showed to improve deformability [12]. Additionally, Rho Kinase plays an important role in erythrocyte deformability when a specific inhibitor, Y-27632, increased erythrocyte deformability by inducing ATP release from these cells [13].

Red blood cells (RBC) deformability is a product of hydration, cytoskeletal proteins and structure, metabolism, vesiculation, adaptive responses and hemoglobin content with numerous techniques to measure directly or indirectly this feature like osmotic fragility test (OFT) [14]. OFT is often performed to help diagnosis of hereditary hemolytic diseases [15], based on the fact that controlling intracellular volume in a normal cell requires activation of diverse signaling pathways and transmembrane enzymes that control ion flux across the cell $[16,17]$. Therefore, the question that lead this work was whether TSH modulates erythrocytes volume regulation and, if does, which signaling is involved in this modulation.

\section{Methodology}

\section{Samples}

Collection of human blood samples for this study was conducted according to the protocols approved by the Research Ethics Committee of the Federal University of Rio de Janeiro (Protocol 2.889.952) and the project is registered in Brazil Platform under the CAAE number 88140418.5 .0000 .5699 . The samples analyzed in this study were obtained from men and women and everyone was informed about the study and those who agreed to participate completed the written informed consent form for the collection of samples and subsequent use. Those with any hemoglobinopathies and those taking controlled medication were excluded. Blood samples were collected in anticoagulant tubes with EDTA by puncture in antecubital fossa.

\section{Haemolysis assay}

Blood was collected in $4 \mathrm{~mL}$ EDTA tubes. These tubes were centrifuged for 10 minutes at approximately 3,000 rpm. After this, the plasma and buffy coat was removed and discarded. The RBC was washed with PBS (phosphate buffered saline) three times (tubes were homogenized by inversion and centrifuged in the same parameters as above). Wide range of $\mathrm{NaCl}$ concentrations $(0.1 \%-0.9 \%)$ was added, followed by TSH in four concentrations (1, 2, 3 and $5 \mathrm{mIU} / \mathrm{L})$, and $\mathrm{RBC}$, resulting in an experiment with a final volume of $300 \mu \mathrm{l}$ and $1 \%$ hematocrit. The tubes were placed in the water bath, 37 ${ }^{\circ} \mathrm{C}$, and all experiments was incubated for one hour with hormone whether combined or not with inhibitors or activators, centrifuged for 10 minutes, $10,000 \mathrm{rpm}$ and the supernatant were carefully removed and pipetted $(200 \mu l)$ into the 96 -well plate. The reading was made in an Elisa reader (Tecan GENios ${ }^{\circledR}$ ) at $540 \mathrm{~nm}$ absorbance.

\section{Hemolysis with TSH, in different concentrations, with AICAR (1 mM), Wortmannin (10 $\mu \mathrm{M})$ and Akt $1 / 2$ inhibitor $(1 \mu \mathrm{M})$}

The same procedure of common hemolysis was performed, however, 5-Aminoimidazole-4-carboxamide 1- $\beta$-D- ribofuranoside, Acadesine, N1-( $\beta$-D-Ribofuranosyl)-5-aminoimidazole-4-carboxamide (AICAR), wortmannin and Akt 1/2 inhibitor (1,3-Dihydro-1-(1-)(4-(6phenyl-1H- imidazo[4,5-g]quinoxalin-7-yl)phenyl)methyl)-4-piperidinyl)-2H-benzimidazol-2-one trifluoroacetate salt hydrate) was added. The amount of $\mathrm{NaCl}$ was recalculated to maintain the final volume of $300 \mathrm{Bl}$ and $1 \%$ hematocrit and next experiments followed the same methodology as the previously mentioned Hemolysis; however, they were only performed with the concentration of $0.4 \% \mathrm{NaCl}$. $0.1 \% \mathrm{NaCl}$ was used as a $100 \%$ hemolysis control, without adding any substance.

\section{Statistical analysis}

GraphPad Prism 5 was used to plot the graphs and to perform statistical analysis, with all data expressed as Mean \pm SEM. For all experiments, an ANOVA with Tukey's post-test was used for analysis of the significant differences ( ${ }^{*}$ for $p<0.05,{ }^{* *}$ for $p<0.01$ and ${ }^{* * *}$ for $p<$ 0.001 , when compared to control and \# for $p<0.05$, \#\# for $p<0.01$ and \#\#\# for $p<0.001$, when compared to same TSH concentration without signaling pathway modulators) with a confidence interval of $95 \%$.

\section{Results}

\section{Osmotic fragility assay}

Changing concentrations of $\mathrm{NaCl}$ from 0.1 to $0.9 \%$ was accompanied by marked hemolysis in very low sodium chloride concentrations of $0.1,0.2,0.3$ and $0.4 \%$. We took $0.1 \%$ as $100 \%$ of hemolysis and compared the amount of subsequent hemolysis that ranged around 

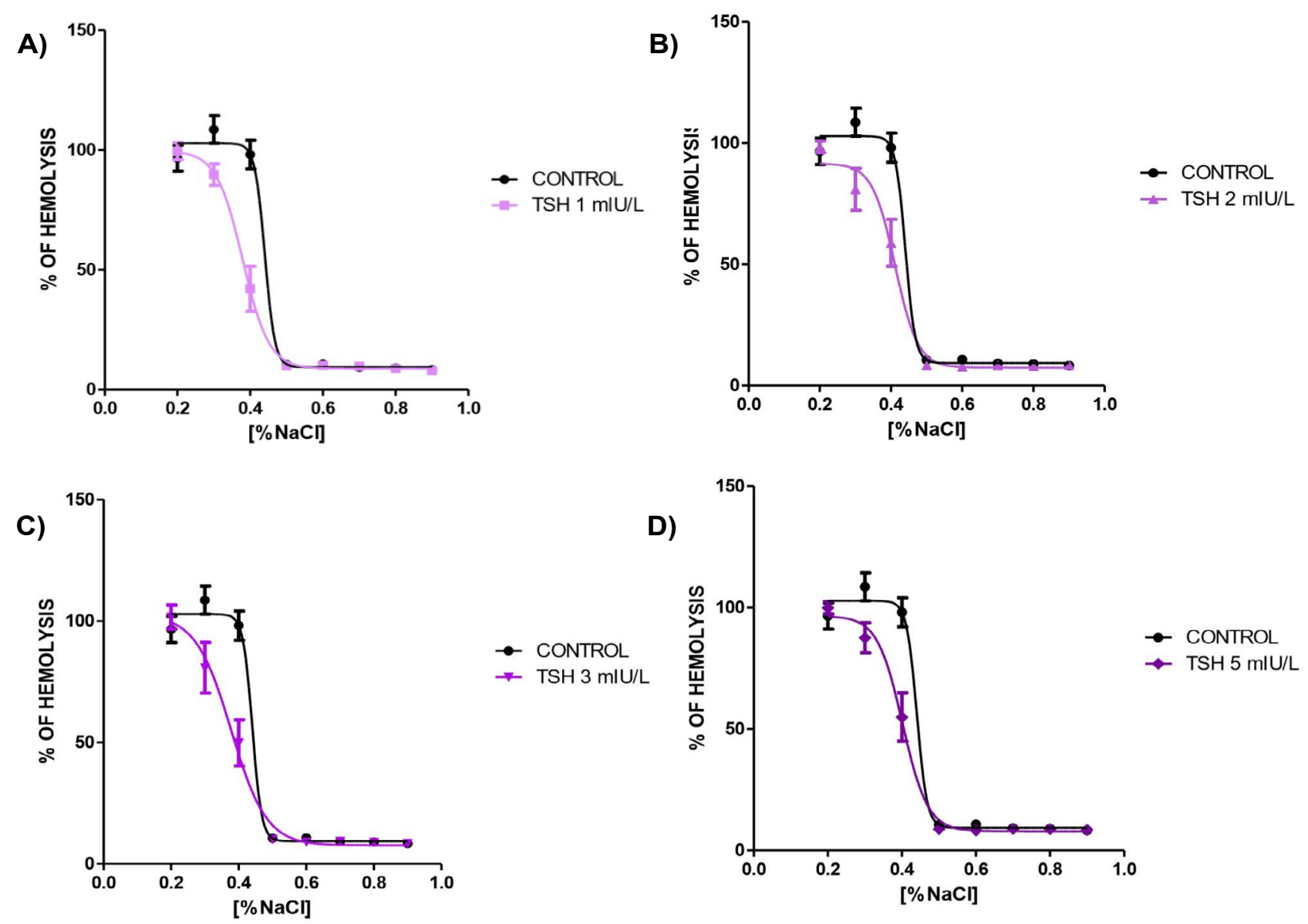

Figure 1: A, B, C, D, Osmotic fragility curve of human blood treated with $T S H$ 1, 2, 3 and $5 \mathrm{mIU} / \mathrm{L}$ for one hour, respectively. $\mathrm{N}=5$ and all experiments was performed in triplicate.

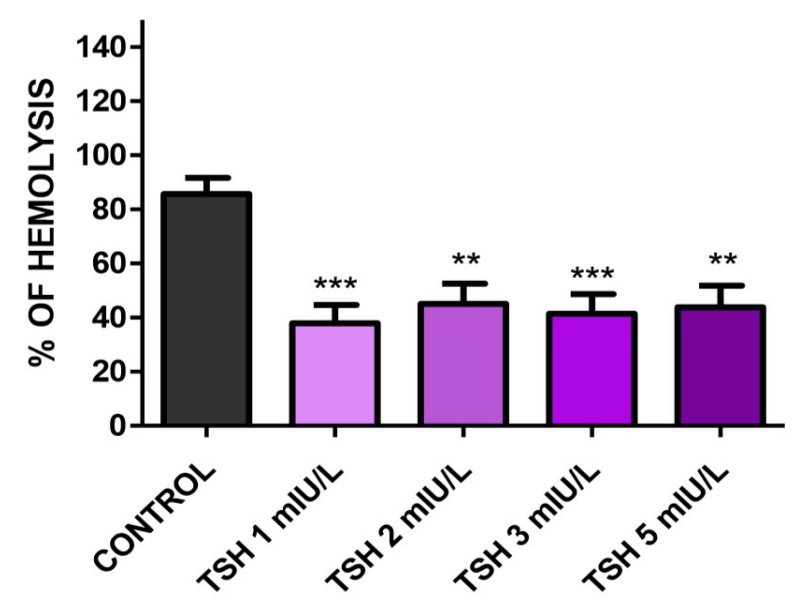

Figure 2: Osmotic fragility in $\mathrm{NaCl} 0.4 \%$ treated with $\mathrm{TSH}$ $1,2,3$, and $5 \mathrm{mIU} / \mathrm{L}$ for one hour. There was decrease in hemolysis in all TSH concentrations: $37.9675 \%, 45.0328 \%$, $41.4301 \%$ and $43.8512 \%$, respectively. $\mathrm{N}=7$ and all experiments was performed in triplicate. Values are mean \pm SEM. ${ }^{*} p<0.05,{ }^{* *} p<0.01$ and ${ }^{* * *} p<0.001$ vs. control.

$100 \%$ in low sodium chloride concentrations control curves showed in (Figure 1A, Figure 1B, Figure $1 \mathrm{C}$ and Figure 1D), where $0.2 \% \mathrm{NaCl}$ gives $96.58 \%, 0.3 \%$ gives $108.59 \%$ and $0.4 \%$ gives $98.12 \%$ of hemolysis in control curve. There is a substantial decrease in hemolysis in 0.5 to $0.9 \%$ of $\mathrm{NaCl}$ in control condition of $10.58 \%, 10.79 \%$, $9.29 \%, 9.01 \%$ and $8.37 \%$ of hemolysis respectively. When TSH $1 \mathrm{mIU} / \mathrm{L}$ was added to the media (Figure 1A), there was a left shift of the curve with statistically decreased hemolysis in $0.3 \%$ and $0.4 \%$ of $\mathrm{NaCl}(89.75 \%$ and $67.13 \%$, respectively) compared to control curve. TSH 2 mIU/L (Figure 1B) exhibited a 79.67\% of hemolysis in $\mathrm{NaCl} 0.4 \%$ and higher concentrations of the hormone followed the same pattern with decreased hemolysis in the same $0.4 \% \mathrm{NaCl}$ concentration $(78.33 \%$ for $3 \mathrm{mIU} / \mathrm{L}$ of TSH in Figure $1 \mathrm{C}$ and $84.88 \%$ for $5 \mathrm{mlU} / \mathrm{L}$ in Figure 1D).

Interestingly, in $\mathrm{NaCl} 0.4 \%$ there was a statistically significantly reduce in hemolysis in all TSH concentrations (Figure 2) pointing that the hormone act reducing osmotic fragility in osmotic stressed erythrocytes.

\section{TSH signaling pathway trigged}

Adding AMPK activator $1 \mathrm{mM}$ AICAR to $\mathrm{NaCl} 0.4 \%$ media lead us to verify the influence of this pathway in TSH-reduced hemolysis. As shown in Figure 3, AICAR blunted the effect of TSH in all concentrations studied, with 1, 2, 3 and $5 \mathrm{mIU} / \mathrm{L}$ displaying 91.96\%, 92.21\%, $86.14 \%$ and $86.76 \%$ of hemolysis, respectively. This was statistically significant when compared to control and when each concentration after AICAR introduction was 


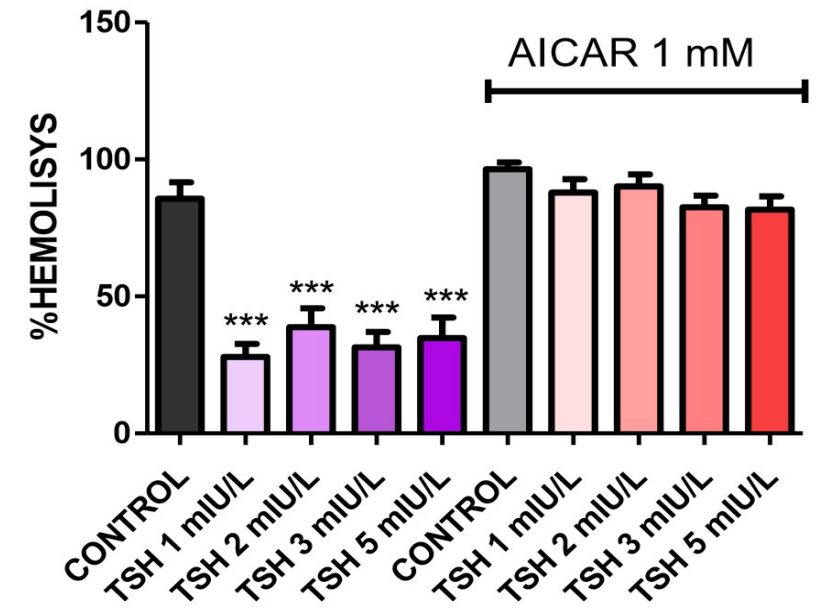

Figure 3: Osmotic fragility in $\mathrm{NaCl} 0.4 \%$ treated with AICAR plus TSH 1, 2, 3, and $5 \mathrm{mIU} / \mathrm{L}$ for one hour. AICAR reversed the effect of TSH in all concentrations: $91.96 \%$, $92.21 \%, 86.14 \%$ and $86.76 \%$, respectively. $\mathrm{N}=4$. Values are mean \pm SEM. ${ }^{*} p<0.05,{ }^{* *} p<0.01$ and ${ }^{* * *} p<0.001$ vs.

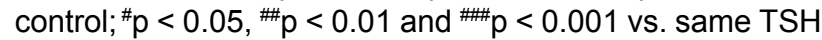
concentration not treated with AICAR.

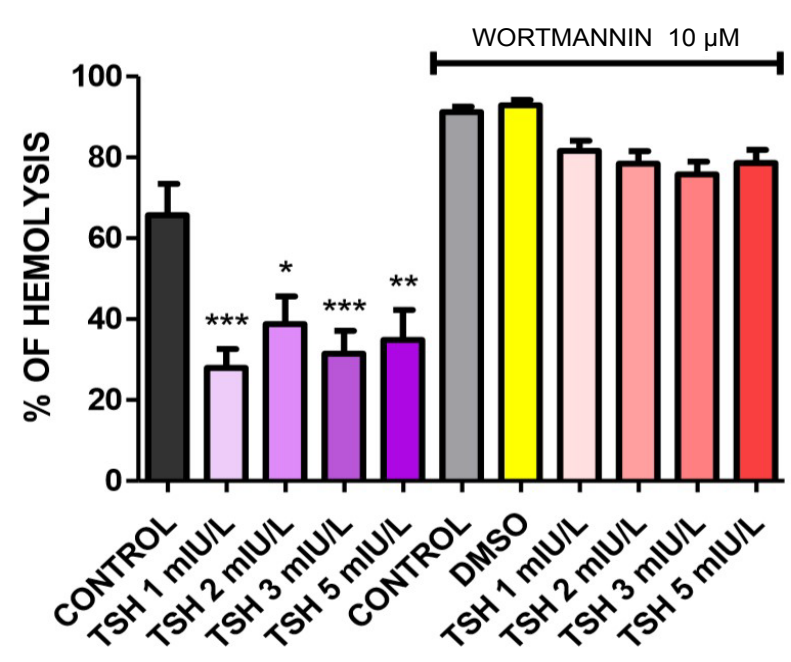

Figure 4: Osmotic fragility in $\mathrm{NaCl} 0.4 \%$ treated with Wortmannin plus TSH 1, 2, 3, and $5 \mathrm{mIU} / \mathrm{L}$ for one hour. All concentrations had the effect of TSH reversed by Wortmannin (81.73\%, $78.41 \%, 75.80 \%$ and $78.64 \%$, respectively) when compared to control and when compared paired TSH observations. $\mathrm{N}=3$ and all experiments was performed in triplicate. Values are mean \pm SEM. ${ }^{*} p<0.05,{ }^{* *} p<0.01$ and ${ }^{* * *} p<0.001$ vs. control; ${ }^{\#} p<0.05,{ }^{\#} p<0.01$ and ${ }^{\# \# p} p<0.001$ vs. same TSH concentration not treated with wortmannin.

compared to the same concentration without AICAR.

PI3K inhibitor wortmannin in $10 \mu \mathrm{M}$ was used to assess the involvement of PI3K activation. As shown in Figure 4, wortmannin reversed the effects of TSH in all concentrations with $81.73 \%, 78.41 \%, 75.80 \%$ and $78.64 \%$ for 1, 2, 3 and $5 \mathrm{mIU} / \mathrm{L}$ respectively with statistically difference when compared to control and when compared to paired concentrations of TSH.

As for possible involvement of Akt pathway, we also

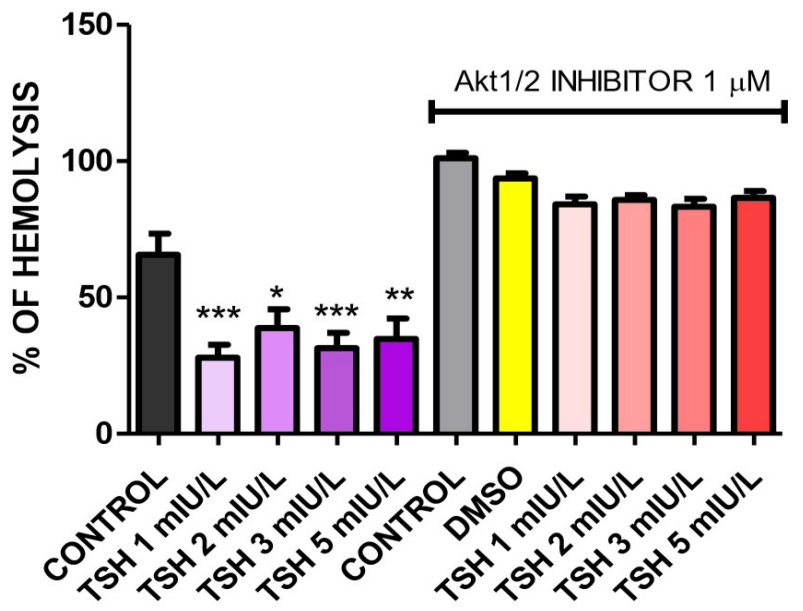

Figure 5: Osmotic fragility in $\mathrm{NaCl} 0.4 \%$ treated with Akt1/2 inhibitor plus TSH 1, 2, 3, and $5 \mathrm{mIU} / \mathrm{L}$ for one hour. The inhibitor reversed the observed diminished hemolysis when compared to control, with $84.21 \%, 85.78 \%, 83.36$ and $86.57 \%$ respectively. $\mathrm{N}=3$ and all experiments was performed in triplicate. Values are mean \pm SEM. " $p<0.05$, " $p$

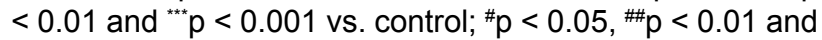
${ }^{\#} \mathrm{p}<0.001$ vs. same TSH concentration not treated with Akt $1 / 2$ inhibitor.

measured hemolysis with Akt $1 / 2$ inhibitor in $1 \mathrm{mM}$ concentration as displayed in Figure 5. In the same way seen in previous experiments, use of the inhibitor reversed the observed diminished hemolysis when compared to control, with $84.21 \%, 85.78 \%, 83.36 \%$ and $86.57 \%$ amount of hemolysis and statistical difference compared between TSH concentrations too.

\section{Discussion}

Erythrocyte volume control is essential for its proper function and, therefore, for life: Overhydration or hypohydration are common fate of diseases involving primarily erythrocytes as seen in plasmodium infection, alcohol intoxication, sickle cell disease, hereditary spherocytosis and thalassemia [18-21]. Considering this, although lack of organelles and nuclei, erythrocytes access sophisticated ways to control ion flux. $\mathrm{Na} / \mathrm{K}^{+}-\mathrm{AT}-$ Pase is one of the key modulators of cell volume with recommendation to be one of the predictors to disease diagnosis and by being modulated by hormones and xenobiotics [22-25]. Huisjes in an elegant review exposed the importance of not only $\mathrm{Na}^{+} / \mathrm{K}^{+}-\mathrm{ATP}$ ase but calcium pumps (PCMA I and PCMA 14 ), $\mathrm{Na}^{+}-\mathrm{K}^{+}-2 \mathrm{Cl}$ cotransporter, $\mathrm{K}^{+}-\mathrm{Cl}^{-}$cotransporter, $\mathrm{Na}^{+} / \mathrm{H}^{+}$exchanger, $\mathrm{Cl}^{-}-\mathrm{HCO}_{3}^{-}$exchanger, Gardos channel, and others transporters [14]. Also, in the same review, special attention was payed to methods and techniques for measuring red blood cell deformability, being one of them, even with disadvantages as all methods, the osmotic fragility test [14].

In this study, we assessed the effects of TSH in controlling red cell volume using the simple OFT technique. There was a significant reduction in hemolysis in RBC treated with TSH 1, 2, 3 and $5 \mathrm{mIU} / \mathrm{L}$ in $0.4 \% \mathrm{NaCl}$, show- 
ing that TSH is able to protect lysis even in a very hostile media. Although literature presents an increase in osmotic fragility when animal models are subjected to experimental (drug-induced) hypothyroidism, our data shows that TSH levels are positively correlated with erythrocyte survival under hypotonic conditions in an isolated system $[26,27]$. This can be due to adverse experimental conditions of animal model with also reported by these authors increased oxidative stress. Nevertheless, is important to highlight that erythrocytes employed in this study was from euthyroid individuals, which might be different from hypothyroid erythrocytes.

TSH is classically associated to CAMP/PKA and PLC/ PKC signaling pathway [28] and others studies points to alternative pathways like activation of ERK $1 / 2$ and NFKB [29]. In an attempt to elucidate possible signaling pathways that can be trigged by TSH in this specific system, we added AICAR, an AMPK activator, to assess whether the late is involved in TSH- mediated effects. We notice that AICAR blunted the protection in all concentrations studied, indicating that AMPK activity is suppressed by TSH treatment. This is in accordance with literature when Shudong, et al. reported that AICAR blocks the TSH- induced expression of specific genes in liver [30]. Besides, Thali and co- workers reported the presence of AMPK in red blood cell lysates [31] and AMPK-deficient mice exhibited an increased hemolysis resistance around $150 \mathrm{mOsmol} / \mathrm{L}$ (correspondent to $0.4 \% \mathrm{NaCl}$ ) when compared to wild-type control model [32], ratifying our findings.
In order to continue searching for other proteins modulated by TSH, we assessed PI3K involvement by adding wortmannin, a specific inhibitor of this kinase. Our result showed that wortmannin also reverted the protection promoted by TSH in all concentrations studied, revealing the link between TSH and PI3K in erythrocytes. Jafari, et al. demonstrated the importance of $\mathrm{PI} 3 \mathrm{~K}$ in differentiation and maturation of RBC [33]; insulin can also activates this pathway in order to prevent ATP release from erythrocytes [34]. It was also reported that pharmacological inhibition of PI3K pathway led to reduced erythrocyte deformability through reduced NO production, confirming our results that shows increased osmotic resistance and indirect increase in deformability $[14,35]$.

As a sequence of PI3K pathway, we assayed the activation of Akt in this system and confirmed, as expected, that use of Akt $1 / 2$ inhibitor recoil the protection seen with TSH in all concentrations. Impaired erythrocyte deformability by $\mathrm{O}_{2}^{-}$was reported to be due to impaired Akt activation [12] as well as NO Activation upstream Akt kinase improved deformability of erythrocytes, also highlighting the data found in the present work.

\section{Conclusion}

Together, our data points that TSH in 1 to $5 \mathrm{mIU} / \mathrm{L}$ improves RBC resistance to hemolysis, as an indirect measure of deformability, and this effect is made by inhibiting AMPK-dependent pathway and concomitant activation of PI3K/Akt signaling pathway, as show in Figure 6.

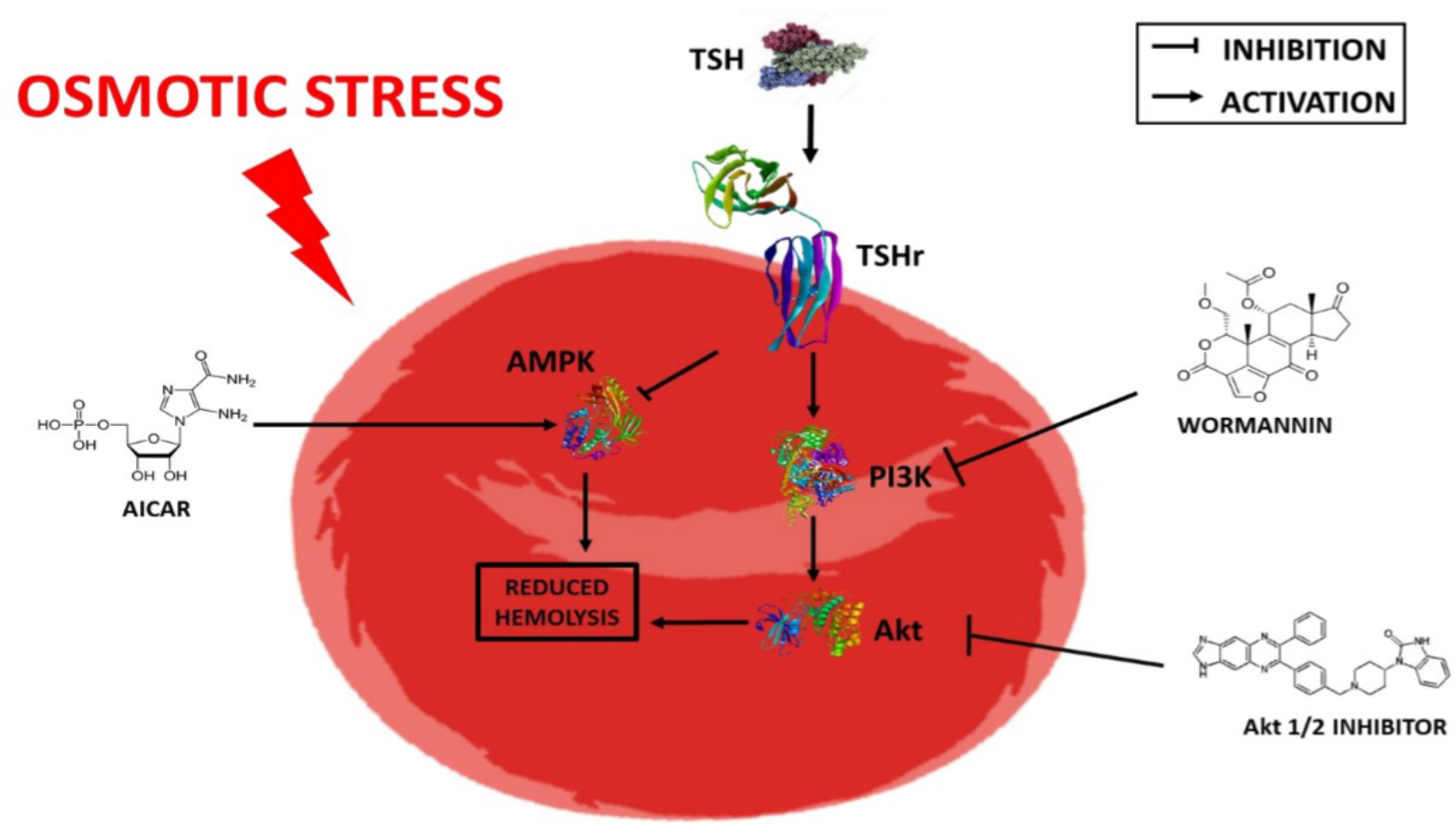

Figure 6: TSH ameliorates erythrocyte resistance to hemolysis. When subjected to an osmotic stress situation, TSH binds to its receptor (TSHr), on the erythrocyte membrane, inhibiting AMPK-dependentpathway (stimulatedby AICAR) and concomitantly activates the PI3K (inhibited by wortmannin)/Akt (inhibited by Akt $1 / 2$ inhibitor) signaling pathway. 


\section{Declarations of Interest}

There is no conflict of interest.

\section{Acknowledgements}

We thank FAPERJ, FUNEMAC, CAPEs and CNPq for financial support.

\section{Grant Support}

This study was supported by Fundação Carlos Chagas Filho de Amparo à Pesquisa do Estado do Rio de Janeiro (JCNE-FAPERJ, E-26/201.520/2014; Edital SediadasFAPERJ, E-26/010.000175/2016), Conselho Nacional de Desenvolvimento Científico (CNPq) and Coordenação de Aperfeiçoamento de Pessoal de Nível Superior (CAPES/ Ciências sem Fronteiras/PVE/88881.062218/2014-0), who supported the scholarship.

The funders had no role in the study design, data collection and analysis, decision to publish, or preparation of the manuscript.

\section{Disclosure Statement}

No competing financial interests exist.

\section{Statement}

Each author contributed in equal parts for this manuscript.

\section{References}

1. Narumi S, Hasegawa T (2015) TSH resistance revisited Endocr J 62: 393-398.

2. Yavuz S, Salgado Nunez Del Prado S, Celi FS (2019) Thyroid hormone action and energy expenditure. J Endocr Soc 3: $1345-1356$.

3. Korta P, Pocheć E (2019) Glycosylation of thyroid-stimulating hormone receptor. Endokrynol Pol 70: 86-100.

4. Vella V, Malaguarnera R (2018) The emerging role of insulin receptor isoforms in thyroid cancer: clinical implications and new perspectives. Int J Mol Sci 19.

5. Martinez-deMena R, Anedda A, Cadenas S, Obregon MJ (2015) TSH effects on thermogenesis in rat brown adipocytes. Mol Cell Endocrinol 404: 151-158.

6. Bell A, Gagnon A, Dods P, Papineau D, Tiberi M, et al. (2002) TSH signaling and cell survival in 3T3-L1 preadipocytes. Am J Physiol Cell Physiol 283: 1056-1064.

7. Crisanti P, Omri B, Hughes E, Meduri G, Hery C, et al. (2001) The expression of thyrotrop in receptor in the brain. Endocrinology 142: 812-822.

8. Li Y, Wang L, Zhou L, Song Y, Ma S, et al. (2017) Thyroid stimulating hormone increases hepatic gluconeogenesis via CRTC2. Mol Cell Endocrinol 446: 70-80.

9. Balzan S, Nicolini G, Forini F, Boni G, Del Carratore R, et al. (2007) Presence of a functional TSH receptor on human erythrocytes. Biomed. Biomed Pharmacother 61: 463-467.

10. Nicolini G, Balzan S, Colzani R, Scarlattini M, Taddei MC, et al. (2004) Erythrocyte Na/K-ATPase is increased in subjects with subclinical hypothyroidism. Clin Endocrinol (Oxf.) 60: 705-710.
11. Sun S, Peng Y, Liu J (2018) Research advances in erythrocyte regeneration sources and methods in vitro. Cell Regen Lond Engl 7: 45-49.

12. Kuck L, Grau M, Bloch W, Simmonds MJ (2019) Shear stress ameliorates superoxide impairment to erythrocyte deformability with concurrent nitric oxide synthase activation. Front Physiol 10: 36.

13. Thuet KM, Bowles EA, Ellsworth ML, Sprague RS, Stephenson AH (2011) The rho kinase inhibitor Y-27632 increases erythrocyte deformability and low oxygen tension-induced ATP release. Am J Physiol Heart Circ Physiol 301: H1891-H1896.

14. Huisjes R, Bogdanova A, van Solinge WW, Schiffelers RM, Kaestner L, et al. (2018) Squeezing for life - Properties of red blood cell deformability. Front Physiol 9: 656.

15. Bianchi P, Fermo E, Vercellati C, Marcello AP, Porretti L, et al. (2012) Diagnostic power of laboratory tests for hereditary spherocytosis: a comparison study in 150 patients grouped according to molecular and clinical characteristics. Haematologica 97: 516-523.

16. Sugie J, Intaglietta M, Sung LA (2018) Water transport and homeostasis as a major function of erythrocytes. Am J Physiol Heart Circ Physiol 314: H1098-H1107.

17. Thomas SL, Bouyer G, Cueff A, Egée S, Glogowska E, et al. (2011) Ion channels in human red blood cell membrane: actors or relics? Blood Cells Mol Dis 46: 261-265.

18. Allen RJ, Kirk K (2004) Cell volume control in the plasmodium-infected erythrocyte. Trends Parasitol 20: 7-10.

19. Demidchik L, Kolesnikova Y, Muravlyova L, Molotov-Luchanskiy V, Kluyev D, et al. (2019) The oxidized proteins and activity of the $\mathrm{Cl}-/ \mathrm{HCO} 3-$ exchanger in erythrocytes of patients with acute alcohol intoxication. Acta Biochim Pol 66: 351-354.

20. Hermann PB, Pianovski MA, Henneberg R, Nascimento AJ, Leonart MS (2016) Erythrocyte oxidative stress markers in children with sickle cell disease. J Pediatr (Rio J) 92: 394-399.

21. Liao L, Deng ZF, Qiu YL, Chen P, Chen WQ, et al. (2014) Values of mean cell volume and mean sphered cell volume can differentiate hereditary spherocytosis and thalassemia. Hematology 19: 393-396.

22. Mishra N, Rizvi SI (2012) Quercetin modulates $\mathrm{Na}(+) / \mathrm{K}(+)$ ATPase and sodium hydrogen exchanger in type 2 diabetic erythrocytes. Cell Mol Biol (Noisy-le-grand) 58: 148-152.

23. Omar AK, Ahmed KA, Helmi NM, Abdullah KT, Qarii MH, et al. (2017) The sensitivity of $\mathrm{Na}+\mathrm{K}+$ ATPase as an indicator of blood diseases. Afr Health Sci 17: 262-269.

24. Singh P, Kesharwani RK, Misra K, Rizvi SI (2015) The modulation of erythrocyte $\mathrm{Na}(+) / \mathrm{K}(+)$-ATPase activity by curcumin. J Adv Res 6: 1023-1030.

25. Tekin N, Akyüz F, Temel HE (2011) NO levels in diabetes mellitus: Effects of I-NAME and insulin on LCAT, $\mathrm{Na}(+) / \mathrm{K}(+)$ ATPase activity and lipid profile. Diabetes Metab Syndr 5: 191-195.

26. Dariyerli N, Toplan S, Akyolcu MC, Hatemi H, Yigit G (2004) Erythrocyteosmotic fragility and oxidative stress in experimental hypothyroidism. Endocrine 25: 1-5.

27. Toplan S, Dariyerli N, Ozdemir S, Ozcelik D, Zengin EU, et al. (2013) Lithium-induced hypothyroidism: oxidative stress and osmotic fragility status in rats. Biol Trace Elem Res 152: $373-378$ 
28. Huang $H$, Shi $Y$, Liang B, Cai $H$, Cai $Q$ (2017) lodinated TG in thyroid follicular lumen regulates TTF-1 and PAX8 expression via TSH/TSHR signaling pathway. J Cell Biochem 118: 3444-3451.

29. Di Cerbo A, Pezzuto F, Di Cerbo A (2017) Growth hormone and insulin-like growth factor 1 affect the severity of Graves' disease. Endocrinol Diabetes Metab Case Rep.

30. Liu S, Jing F, Yu C, Gao L, Qin Y, et al. (2015) AICAR-Induced activation of AMPK Inhibits TSH/SREBP-2/HMGCR pathway in liver. PLoS One 10: e0124951.

31. Thali RF, Tuerk RD, Scholz R, Yoho-Auchli Y, Brunisholz RA, et al. (2010) Novel candidate substrates of AMP-activated protein kinase identified in red blood cell lysates. Biochem Biophys Res Commun 398: 296-301.

32. Föller M, Sopjani M, Koka S, Gu S, Mahmud H, et al. (2009)
Regulation of erythrocyte survival by AMP-activated protein kinase. FASEB J 23: 1072-1080.

33. Jafari M, Ghadami E, Dadkhah T, Akhavan-Niaki H (2019) PI3k/Akt signaling pathway: Erythropoiesis and beyond. J Cell Physiol 234: 2373-2385.

34. Hanson MS, Stephenson AH, Bowles EA, Sprague RS (2010) Insulin inhibits human erythrocyte cAMP accumulation and ATP release: role of phosphodiesterase 3 and phosphoinositide 3-kinase. Exp Biol Med Maywood 235: 256-262.

35. Suhr F, Brenig J, Müller R, Behrens H, Bloch W, et al. (2012) Moderate exercise promotes human RBC-NOS activity, NO production and deformability through Akt kinase pathway. PLoS One 7: e45982. 